\title{
La Respuesta de San Agustín Ante la Duda Escéptica: en Torno a la Posibilidda de EnSEÑanza Y Aprendizaje a Través de Signos
}

\author{
St. Augustine's Answer to the Skeptical Doubt about the \\ Teaching's Possibility and Learning through Signs
}

\author{
Maximiliano Prada Dussán" \\ Universidad Pedagógica Nacional de Colombia \\ aprada@pedagogica.edu.co
}

Fecha de recepción: 1 de julio de 2014

Fecha de aceptación: 7 de agosto de 2014

\section{Resumen}

Se expone la forma como Agustín responde a la duda escéptica, en torno a la posibilidad de enseñanza y aprendizaje a través de la locutio, y se muestra cómo en su respuesta asume la duda escéptica, pero reafirma la necesidad de la emisión de signos, tanto desde el terreno de una teoría del conocimiento, a través de la relación de los signos con el commemorare y el quaerere, como desde el campo ético, por vía del enlace de los signos con caritas.

Palabras clave: Enseñanza-aprendizaje, Escepticismo, San Agustín, Signo.

\section{Abstract}

This paper shows the way that Augustine faces the skeptical doubt, about the utility of locutio, in the teaching and learning processes. It reveals that Augustine accepts the skeptical doubt, but justifies the necessity of locutio, both from a knowledge

\footnotetext{
* Doctor en Filosofía. Profesor Licenciatura en Filosofía, Universidad Pedagógica Nacional de Colombia. Coordinador proyecto de investigación: "Arte de vivir, arte de morir: presupuestos para una filosofía como modo de vida”. UPN ${ }^{2014}$. Grupo Filosofía y Enseñanza de la Filosofía. aprada@pedagogica.edu.co
} 
theory and an ethical perspective. In the former, signs are related with the commemorare and quaerere and in the last one, they are linked with caritas.

Keywords: Sign, St. Augustine, Skepticism, Teaching-Learning.

\section{Introducción}

Agustín es fuente necesaria para comprender distintas discusiones en torno a la educación, propias de la antigüedad tardía y de la primera fase de la Edad Media. Entre muchos aspectos que abordó este filósofo africano, nos interesa rastrear el trato que hizo de la duda escéptica sobre la posibilidad de enseñanza y aprendizaje por medio de la emisión de signos (locutio $)^{1}$. Mostraremos que Agustín se adscribe a tal duda, pero en lugar de concluir que por ello la locutio es inútil en tales procesos, afirma su necesidad, reasignándole un nuevo rol y valor. La justificación última de la emisión de signos lo obliga a desplazarse de la perspectiva del conocimiento, en donde los signos se relacionan con el recuerdo (commemorare) y la búsqueda (quaerere) hacia la ética, en donde encuentra que la caridad (caritas) es la razón última de dicha emisión.

Desarrollaremos nuestro escrito en tres momentos; en el primero, reconstruiremos la duda escéptica frente a la utilidad de la emisión de signos; en el segundo, rastrearemos la respuesta que dio Agustín a tal duda desde el terreno del conocimiento; finalmente, centraremos nuestra atención en la justificación ética.

\section{La Duda Escéptica Acerca del Papel de los Signos en el Aprendizaje}

En su texto Contra los profesores, Sexto Empírico reconstruye las refutaciones escépticas sobre la posibilidad de que la enseñanza contribuya en el camino de encuentro de la sabiduría -aprendizaje-; estas se dividen en críticas generales y críticas frente a las disciplinas en particular. Dentro de las primeras se encuentra la refutación a cuatro asuntos: "la materia enseñada en cada disciplina, el maestro, el

\footnotetext{
${ }^{1}$ No es nuestra intención en este artículo hacer una exposición completa de la teoría del signo y del lenguaje en Agustín. Nos limitaremos a hacer algunas observaciones en la relación que estos tejen con el aprendizaje. Para una exposición ampliada de la teoría del signo en el africano, véanse los siguientes estudios: Kirwan $\left({ }^{2001}\right)$, Markus, R. A. $\left({ }^{1972}\right)$, Darrell ( $\left.{ }^{1972}\right)$, Rincón $\left({ }^{1992}\right)$, Todorov $\left({ }^{1991}\right)$ y Ando $\left({ }^{2001}\right)$.
} 
discípulo y el método de enseñanza" (1997, p. I. I. 9); dentro de las segundas, la refutación a la consistencia de las disciplinas liberales en sí mismas. De todas ellas nos interesa rastrear la referida al método de enseñanza, que, según el escéptico, se centra en el uso del lenguaje.

Para abordar la crítica al método de enseñanza, Sexto Empírico concede por un momento que exista una materia para enseñar, un maestro y un discípulo. Una vez hecha esta concesión, introduce su crítica por medio de la cual busca mostrar que el lenguaje no es capaz de enseñar; a esta conclusión llega por medio del análisis del papel de los signos. En palabras del escéptico:

En cuanto al lenguaje, o significa algo o no significa nada. Y si no significa nada tampoco enseña nada; si significa algo, lo hará o por naturaleza, o por convención. Pero no significa algo por naturaleza, pues no todos entienden a todos: los griegos a los bárbaros, los bárbaros a los griegos, ni los griegos a los griegos o los bárbaros a los bárbaros. Y si significa algo por convención, es evidente que quienes han previamente aprehendido los objetos a los que las palabras hacen referencia, aprehenderán también dichas palabras, pero no es que estas palabras les enseñen cosas que ignoraban, sino que es como si volvieran la vista a lo que ya sabían, pero quienes aspiren a instruirse en cosas que ignoran no podrán conseguirlo (1997, p. I.IV. 38).

La crítica descarta la posibilidad de que el lenguaje o la locutio -emisión de signos, en este caso, de palabras- enseñe algo en absoluto. Descarta la posibilidad en tres casos de uso de los signos: si quien escucha el signo no conoce el significado, no lo comprende; si conoce el significado, se abren dos posibilidades: la primera, que la unión entre el signo y lo que significa sea de carácter natural, asunto que queda descartado al considerar que la experiencia frente a la diversidad de lenguas muestra que entre ellas no se comprenden; la segunda se abre considerando el carácter convencional de tal relación. Aun en este caso, la posibilidad del signo queda refutada al considerar que para que el signo sea comprendido ya debe conocerse de antemano lo que este significa.

Esta refutación, unida a aquellas de carácter general antes mencionadas, conducen al escéptico a concluir que "es evidente que no existe ni la enseñanza ni nadie que la tenga a su cargo" (1997, p. I.IV. 38). Esto es, si el intercambio de signos, como método de enseñanza, resulta inútil en los procesos de aprendizaje, y si los otros tres elementos generales también son cuestionados, el edificio educativo quedaría, así, desmontado. No tendría sentido sostener los mecanismos de enseñanza que la 
civilización ha construido ${ }^{2}$. En cuanto a los métodos de enseñanza, este es, pues, el panorama conceptual al que se enfrenta Agustín.

\section{Agustín y la Justificación de la Locutio Como un Asunto de Conocimiento}

A pesar de que no hay pruebas que permitan afirmar que Agustín conoció de primera mano los textos de Sexto Empírico, sí se sabe que conoció los planteamientos escépticos por vía de los escritos de Cicerón, tales como Cuestiones Académicas y El Hortensio ${ }^{3}$. En este sentido, conoció la vertiente que deriva de la Media y la Nueva Academia, lideradas respectivamente por Arcesilao y Carnéades. Ya el autor africano se había enfrentado a las dudas escépticas en otros tratados, como el De Academicos ${ }^{4}$ y De Beata Vita, refiriéndose a la posibilidad de la sabiduría y de la vida feliz. También el De Musica se mueve bajo la estela escéptica que cuestiona la existencia misma del tiempo y, por ello, de una disciplina dedicada a este asunto, la música.

En el caso específico que nos ocupa, aunque en sus textos sobre el lenguaje y el signo -De magistro, De Doctrina Christiana, Principia Dialectica y De Trinitate, entre otros-Agustín no manifieste directamente que está refutando críticas escépticas, algunas alusiones sobre el contenido mismo de la crítica contarían a favor de que se trata de una respuesta a dichas cuestiones.

La cuestión es directamente presentada por Agustín en De Magistro; así, bien puede interpretarse este diálogo como un texto enmarcado dentro de la duda escéptica; allí acepta y desarrolla la mentada duda. Si reconocemos un signo como signo de algo, señala, esto se debe a que ya conocemos lo que él significa, y si ya conocemos lo que significa, entonces no necesitamos el signo para conocer lo que pretende enseñar. Del lado inverso, si no se conoce aquello que el signo significa, entonces el signo no opera como tal, pues no tiene significado enlazado; de esta manera, de nada sirve

\footnotetext{
${ }^{2}$ La inutilidad de la emisión de signos es, ello mismo, una cuestión acerca del acto mismo de la comunicación. En efecto, se encuentra aquí la posición de Cratilo, de quien Aristóteles señalara que llegó incluso a negar la eficacia del hablar mismo hacia los demás, pues según aquel, si el habla no tenía un enlace directo con los objetos y si estos no podían ser transmitidos, en virtud de la inestabilidad del mundo, aquella dejaba de ser útil (Cfr. Aristóteles. Metafísica. 1010 a.). La postura de Cratilo está soportada en la noción de inestabilidad del mundo. Sobre este asunto, véase: Pajón Leyra (2009, pp. 139-153).

${ }^{3}$ Aunque Cicerón no concebía a Pirrón dentro del escepticismo, a partir de Enesidemo se reivindica esta figura como heredera del escepticismo. Dentro de esta otra línea se encuentra, a su vez, Sexto Empírico, quien a su turno concibe como escéptica la línea inaugurada por Pirrón (Román, 2007, pp. 28-32). No hay garantías que permitan afirmar que Agustín hubiera conocido de primera mano los textos de Sexto Empírico (O' Daly, Gerard, 2001, p. 159).

${ }^{4}$ En este texto hace un recuento de la historia y de las tesis académicas fundamentales.
} 
emitirlo; así lo expresa Agustín: "Porque, cuando se me da un signo, si sucede que yo no sé de qué cosa es signo, no me puede enseñar nada; $y$, si lo sé, ¿qué aprendo por el signo?"

En el caso que nos ocupa es necesario advertir que la cuestión se centra no en la posibilidad misma de conocer, sino en que el conocimiento se adquiera a través de los signos. Nuestra indagación se centra en este último asunto, no en describir este proceso en su totalidad, aun cuando debamos referirnos a él como presupuesto. En concreto, diremos que para Agustín el conocimiento se da a través de la iluminación, esto es, por la visión directa de las formas que se encuentran en la palabra divina ${ }^{6}$ y en virtud de la gracia divina ${ }^{7}$. Teoría presente también en $D e$ Magistro (2003, p. XII.40) ${ }^{8}$.

Habiendo aceptado la imposibilidad de aprender por medio de signos, Agustín pregunta en De Magistro qué función cumple la locutio. El diálogo inicia con esta pregunta lanzada a Adeodato, su hijo, quien en el texto es su interlocutor: "¿Qué te parece que queremos hacer cuando hablamos?" (2003, p. I.1). La respuesta se expone desde el inicio del diálogo y se sostiene a lo largo de él: “desde ahora afirmo que hay dos motivos para hablar: o que enseñemos (docere) o que recordemos (commemorare) a otros o a nosotros mismos" (2003, p. I.1) ; más adelante, en este mismo texto, añadirá que la locutio motiva también a buscar (quaerere) (p. XI. 36). Analizaremos estas tres funciones en relación con la cuestión planteada.

Inicialmente, tomemos en consideración el docere. Agustín fue maestro en distintas ocasiones de su vida y en distintos lugares, razón por la cual hay numerosas alusiones en sus escritos acerca del acontecimiento de la enseñanza, comprendida en sentido general, y a partir de las distintas modalidades que pueda tomar: piensa en las enseñanzas que los padres y las cuidadoras dan a los niños, las enseñanzas por

\footnotetext{
${ }^{5}$ Agustín, De Magistro (De Mag.) X. ${ }^{33}$. (Citaremos los textos de Agustín por su nombre en latín o por su abreviatura. Para conocer la referencia completa, véase la bibliografía de este artículo). En textos posteriores, Agustín sostiene su adhesión a las tesis escépticas. Véanse por ejemplo De Trinitate (De Trin) X, I. ${ }^{1}$.ss y Confesionum (Confess) I. I. ${ }^{1}$.

${ }^{6}$ Pero nuestra ciencia es Cristo, y nuestra sabiduría es también Cristo. El plantó en nuestras almas la fe de las cosas temporales, y en las eternas nos manifiesta la verdad. Por Él caminamos hacia Él y por la ciencia nos dirigimos a la sabiduría, mas sin apartarnos de la unidad de Cristo, en quien se hallan escondidos todos los tesoros de la sabiduría y de la ciencia”. Agustín. De Trin. XIII. XIX. ${ }^{24}$. Ver también De Mag. XI. ${ }^{38}$.

${ }^{7}$ Como señala Matthews, esta teoría asegura la participación de Dios en el proceso de conocimiento, como garante de que en algún sentido y dentro de lo que en la naturaleza humana es posible, el hombre alcanza, o mejor, es alcanzado por la verdad (Cfr. Matthews, 2001, p. 180).

${ }^{8}$ Ver también: Agustín, De Genesi at litteram. (De gen. ad. litt). XII. XXXI. ${ }^{59}$ y Soliloquiorum (Solil). I. VIII. ${ }^{15}$.

${ }^{9}$ En De Doctrina Christiana (De doctr. chr) Agustín distinguió entre los signos naturales, o aquellos que no se emiten intencionalmente, de los dados, o aquellos que se emiten con la intención de comunicar. II. I. ${ }^{2}$. En De Mag. Agustín analiza solamente los dados. La locutio estaría constituida primordialmente por signos dados.
} 
medio de las cuales los doctos instruyen a los indoctos, las enseñanzas en el interior de los distintos credos, e incluso, la enseñanza de Cristo a la humanidad. No obstante, en el contexto en que lo estamos describiendo, el enseñar (docere) trasciende el significado que se le da a esta palabra dentro de los procesos formales de enseñanza, y se instala como punto de partida de cualquier proceso de comunicación y de adquisición de conocimiento: el docere es comprendido como manifestación exterior del pensamiento. En este sentido, abarca una amplia gama de funciones que cumple la emisión de signos: enseñamos nuestro interior cuando queremos exteriorizar una idea, cuando afirmamos, cuando negamos, cuando preguntamos, cuando expresamos emociones, cunado queremos recordar, motivar, exclamar, insinuar, etc., y cobija también distintas formas de la emisión: el canto, el grito, la oración y la emisión de signos visuales y gestos, como se hace en la lengua de señas ${ }^{10}$.

Las distintas definiciones de signo (signum) que ofrece Agustín a lo largo de sus escritos enfatizan el hecho señalado: que los signos se emiten con el fin de enseñar, de exteriorizar lo que hay en el interior de quien lo emite. Su definición, entonces, enlaza la naturaleza del signo con su función: "toda cosa que, además de la fisonomía que en sí tiene y presenta a nuestros sentidos, hace que nos venga al pensamiento otra cosa distinta" (1969, p. II. I. 1). Del mismo modo, "Nadie usa de las palabras si no es para significar algo con ellas. De aquí se comprende a qué llamo signos, es decir, a todo lo que se emplea para dar a conocer alguna cosa" (1969, p. I.II.2). Así mismo: "No tenemos otra razón para señalar, es decir, dar un signo, sino el sacar y trasladar al ánimo de otro lo que tenía en el suyo aquel que dio tal señal" (1969, p. II.II.3). "Y cuando dirigimos la palabra a otros, añadimos a nuestro verbo interior el ministerio de la voz o algún otro signo sensible, a fin de producir en el alma del que escucha, mediante un recuerdo material, algo muy semejante a lo que en el alma del locutor permanece" (2006, p. IX.VII.12). Con todo, para Agustín resulta claro que la locutio cumple la función de enseñar, docere, en sentido de exteriorizar.

Centremos ahora nuestra atención en el commemorare y el quaerere. Agustín señala que un signo es tal solamente cuando está unido a un significado; esto es, si no existe esa unión, el signo se reduce a ser una mera cosa $(\text { res })^{11}$. En el caso de las palabras,

\footnotetext{
${ }^{10}$ Como afirma Rincón, durante el De Magistro, el verbo enseñar (docere) abarca una amplia gama de significados, tales como commemorare, significare, loqui, ostendere, monstrare, indicare y exhibere, entre otros. Para ampliar esta cuestión (véase Rincón, 1992, pp. 159-161).

11 "Denominamos ahora cosas (res) las que, como son una vara, una piedra, una bestia, y las demás por el estilo, no se emplean también para significar algo" (De doctr. chr. I. II. ${ }^{2}$ ). Un signo (signum), por su parte, es “toda cosa que, además de la fisonomía que en sí tiene y presenta a nuestros sentidos, hace que nos venga al pensamiento otra cosa distinta" (De doctr. chr. II. I. ${ }^{1}$ ).
} 
sin significado estas dejan de ser tales y, por ende, se percibirían como mero ruido. En este sentido, Agustín insiste en que para que un signo sea entendido como tal se requiere que el receptor sepa de antemano su significado. Al percibir el signo, el receptor vuelve sobre sí y trae a la mente lo que ya ha conocido; esto es, recuerda un significado. Hablar tiene, entonces, la función de hacer recordar (commemorare), de volver a traer a la mente aquello que ya se sabe. Pero, ¿qué ocurre en quien percibe un signo pero desconoce su significado? En ocasiones percibimos palabras que, aunque no conozcamos lo que significan, sabemos que efectivamente son palabras, no meros ruidos; sabemos que algo significan porque otros así lo han indicado; cuando esto ocurre, señala Agustín, los signos ofrecen una creencia, esto es, un "conocimiento" o un acercamiento indirecto a la verdad, que requiere ser contrastado a través de la visión directa de las cosas para que constituyan propiamente un conocimiento. En palabras de Jhon Rist, la creencia es un acercamiento de segunda mano, en donde el de primera mano es aquel que se da por visión directa (Cfr. Rist, 1994, p. 31). Es un acercamiento previo, provisional, una mediación que usa signos ante la imposibilidad del encuentro directo con los objetos por conocer. Por ser solo provisional, es un acercamiento que invita a buscar (Agustín, 2006, pp. XI.36 y XIV.46), que alcanza su sentido pleno solo cuando se supera la mediación y se alcanza la visión directa de la verdad.

Con lo anterior se ha mostrado que Agustín acepta las premisas de los escépticos; al igual que ellos, sostiene que quien percibe el signo no alcanza por medio de él la visión directa de los objetos de conocimiento; a lo sumo, recuerda lo que ya sabe o tiene una visión indirecta de ellos. Pero el conocimiento, en tanto es visión directa, no lo consigue por medio de los signos; por este motivo, en De Magistro incluso acepta que ningún ser humano puede ser maestro en sentido estricto, que el único maestro se encuentra en el interior de cada cual (2006, $p p$. XI.36 y XIV.46).

Pero, a diferencia de la radicalidad de las conclusiones escépticas, Agustín no descarta la utilidad de los signos en el proceso comunicativo y de aprendizaje; en efecto, aun el papel de los signos, en quien percibe el signo, consiste en que estos llevan a recordar lo ya conocido y a buscar lo desconocido; en este sentido, se puede afirmar que ha aceptado la crítica escéptica, pero no comparte sus consecuencias. Su réplica no consiste, entonces, en deshacer la crítica, sino en afirmar que aun cuando esta es verdadera, no por eso los signos deben ser descartados de los procesos mencionados; más aún, en escritos posteriores relevará el papel del recuerdo y la búsqueda dentro del proceso de conocimiento ${ }^{12}$.

${ }^{12}$ A parte de lo ya señalado, veáse De Trin. X. I. ${ }^{1}$ y XII. XV. ${ }^{24}$. 


\section{La Justificación Ética de la Locutio}

Pero la aparente solución agustiniana lo lleva ahora a otro callejón. Si enseñar, recordar y buscar son las funciones de los signos, ellos no solo no son suficientes, en el sentido en que no constituyen por sí mismos un conocimiento, sino que, como señalan los críticos, pueden no ser necesarios, en el sentido en que podemos prescindir de ellos, pues si el conocimiento se alcanza por iluminación, esto es, por una visión interior de la palabra divina, entonces pueden no ser requeridos en absoluto. En los términos en que tal discusión se lleva a cabo, los críticos preguntan, ¿por qué Dios no revela directamente el conocimiento a los seres humanos, en lugar de enredarlos en estructuras lingüísticas, culturales y sociales que, aunque se erigen para ello, finalmente no son suficientes? (Agustín, 1969, p. 6). El contexto y los términos en los que está planteada esta cuestión obligan a entrar en argumentos soportados por la raíz judeo-cristiana que asume Agustín, que indagan acerca del plan divino y las razones que llevan a este plan. En efecto, como señala Karla Pollman, el trato agustiniano acerca de los signos no solo se sostiene en su herencia escéptica y estoica, sino que toma elementos también de esta otra tradición señalada (Cfr. Pollmann, 2005, p. 216). Dentro de esta síntesis de tradiciones, nos interesa subrayar sobre todo el horizonte en el que se desenvuelve la respuesta agustiniana a la crítica escéptica y que termina por justificar el acto de la locución. Veamos.

En el prólogo de De Doctrina Christiana, lugar en el que es reseñada la crítica que ahora tratamos, Agustín acepta que Dios bien pudo haber dispuesto la condición humana de modo tal que el conocimiento no estuviera mediado por los actos comunicativos entre los seres humanos; no obstante, propone que, aun cuando Dios pudo haberlo dispuesto de ese modo, prefirió que en este proceso existiera mediación humana: "Todas estas cosas pudieron haber sido hechas por medio de un ángel [se refiere a anuncios divinos], pero entonces la condición humana quedaría rebajada, al parecer que Dios no quería administrar (ministrare) su palabra a los hombres por medio de hombres" $(1969$, p. 6). La cuestión se dirige entonces a indagar por qué es relevante la mediación humana, la administración de la palabra; en último término, por qué es relevante la locutio -el comunicar, aprender y enseñar entre unos y otros-, siendo que, como ya se ha mostrado, no tiene justificación última en una descripción perteneciente a la teoría del conocimiento.

Al no encontrar justificación última en una teoría del conocimiento, la respuesta de Agustín se desplaza al terreno ético; la razón de esto se encuentra, dice el autor africano, en que de no haber mediación no habría lugar para el vínculo amoroso entre personas: "En fin, la misma caridad que estrecha mutuamente a los hombres, 
con el nudo de la unidad, no tendría entrada en las almas para fundirlas y como mezclarlas entre sí, si los hombres nada aprendieran por medio de los hombres" (1969, p. 6). Así, en consideración de Agustín, sin emisión de signos, sin intercambio comunicativo, sin que cada cual enseñe a otros lo que hay en su interior, sin procesos de enseñanza y aprendizaje entre humanos, no habría relación entre seres humanos, y sin ella no habría cabida para la caridad. Señalemos las vías que toma este enlace entre la locutio y la caridad.

Por un lado, este asunto exige retornar al punto de vista de quien emite el signo. Al situar el análisis de esta figura en el terreno ético, Agustín comprende que los distintos propósitos y formas de la emisión de signos, las cuales reseñamos con anterioridad, se inscriben dentro de la caridad: en efecto, el mandato de la caridad exige ayudar a los demás a que encuentren la verdad. En este marco de comprensión, los signos se emiten de modo que los demás la encuentren, bien sea por medio del recuerdo o la búsqueda. El docere es, pues, fruto de la caridad, esto es, se realiza por el amor universal que implica búsqueda del bien del otro. Hacia este carácter ético de los signos conduce Agustín la crítica a los maestros, en De Magistro, y la crítica a los maniqueos, en Confessionum: mientras el amor a sí mismo los lleva a dominar a los otros, buscando únicamente su propio beneficio, la caridad los llevaría a estar al servicio de los demás. Sin la caridad, la relación maestro-estudiante no es más que una relación de dominación, y los signos, el instrumento por el cual se realiza ese dominio. Es también lo que mueve al ejercicio mismo de confesar: dar a conocer a los demás la experiencia interna; ejercicio que mueve la escritura de Confessionum.

Pero el vínculo reseñado no implica solamente la perspectiva del emisor del signo. Agustín dirige sus reflexiones hacia la idea según la cual la locutio es el presupuesto de la comunicación con los otros y es posibilidad de la vida en común, toda vez que consiste en una exteriorización de un contenido interno, de modo que quien escucha el signo conozca lo que el emisor tiene dentro de sí; este último, a su turno, comprende el signo si conoce de antemano su significado. Por este carácter que tiene la locutio de presentar exteriormente lo que cada cual tiene internamente, y de la posibilidad de cierta comunión de contenidos entre los interlocutores, Agustín considera el lenguaje como aglutinante (2006, p. X.I.2). A este respecto, en su consideración, aprender una lengua o conocer un conjunto de signos introduce a quien lo aprende dentro de un grupo determinado; un grupo que tiene cierta comprensión del signo y que lo exterioriza por medio de signos. Por ello, una comunidad es, en este sentido, comunidad simbólica: es una comunidad que comparte significados y comparte cierta relación entre estos y los signos. Bajo este 
supuesto, Markus considera que el De Doctrina Christiana puede ser concebido como un texto en el que Agustín estudia la comunidad cristiana como subcultura dentro de una cultura romana mayoritaria, en tanto comunidad simbólica, esto es, en tanto comunidad que tiene cierta comprensión de los signos, de sus relaciones entre sí, de sus relaciones con los significados y con quienes hacen uso de ellos (Cfr. Markus, 1995, pp. 104 ss).

Tal estructura lingüística que soporta la vida en común revela el enlace último con la caridad. Los significados compartidos por una comunidad son fruto del amor que los soporta: si se trata de la caridad, sus significados descansan en la verdad, si se trata del amor a sí mismos, no es posible alcanzarla. Solo el vínculo de la caridad permite que una comunidad se construya sobre la base de la verdad; a diferencia de la comunidad fundada en el amor a sí mismo -en donde una de sus manifestaciones estaría representada en el relato de la Torre de Babel-, la comunidad fundada en la caridad realiza la vocación humana de vida en común: la Ciudad de Dios (Agustín, 2009 b, p. XIV. XXVIII); sin el vínculo amoroso, pues, el ser humano no consuma su vocación de enlace con los otros. Con todo, dentro del proyecto de la Ciudad de Dios la emisión de signos es fruto de la caridad, está fundada en la verdad y es posibilidad de unión-verdadera-entre los seres humanos.

\section{Conclusión}

En este texto hemos rastreado la respuesta que desarrolla Agustín a la crítica escéptica sobre la utilidad de la emisión de signos en el proceso de aprendizaje; hemos querido mostrar que en dicha respuesta Agustín acepta la crítica de los escépticos, pero difiere en sus conclusiones y consecuencias. Aparte de ello, hemos señalado que el autor africano lleva este asunto a sus consecuencias últimas, tránsito en el cual desplazó la justificación de la locutio desde el terreno del conocimiento hacia el ético, asunto que llevó también a considerar el proceso comunicativo envuelto en tal cuestión. Sostenemos que la perspectiva ética permite a Agustín dar respuesta a las cuestiones acerca de la necesidad de la emisión de los signos en los procesos mencionados; en este sentido, es necesario insistir también en que el trato de Agustín a la duda escéptica no se restringe a lo consignado en De Magistro, sino que se sostiene y desarrolla a lo largo de otras obras, en particular en De Doctrina Christiana y en De Trinitate.

Con John Rist podemos afirmar que, en suma, los signos resultan ser necesarios en el proceso de conocimiento, pero no son suficientes; son necesarios en tanto conducen al recuerdo y a la búsqueda en dicho proceso y permiten el vínculo de la

La respuesta de San Agustín ante la duda escéptica: en torno a la posibilidad de la enseñanza y aprendizaje a través de los signos / Maximiliano Prada Dussán - pp. 198-210 
caridad en el terreno ético; pero no son suficientes en tanto se requiere la intervención divina en uno y otro ámbito; en el primero, a modo de iluminación, y, en el segundo, a modo de origen y posibilidad de la caridad.

\section{Referencias}

Ando, C. (2001). "Signs, Idols and Incarnation in Augustinian Metaphysics". Representations, Vol. 73, No. 1, pp. 24-53. University of California Press. Aristóteles. (1994). Metafísica. Traducción de Carlos García Gual. Madrid: Gredos.

Jackson, D. (1972). "The theory of signs in De Doctrina Christiana". St. Augustine: a collection of critical essays. R. A. Markus (ed.). Nueva York: Anchor Books, pp. 92-147.

Kirwan, C. (2001). "Augustin Philosophy of Language". The Cambridge Companion to Augustine. Eleonore Stump y Norman Kretzman (eds.). Cambridge University Press, pp. 186-204.

Matthews, G. (2001). "Knowledge and illumination". The Cambridge Companion to Augustine. Eleonore Stump y Norman Kretzman (eds.). Cambridge University Press, pp. 171-185.

Markus, R. A. (ed.), (1972). St. Agustine: a collection of critical essays. Nueva York: Anchor Books.

O'Daly, G. (2001). "The response to skepticism and the mecanisms of cognition". Cambridge Company to Augustine. Eleonore Stump y Norman Kretzman (eds.). Cambridge University Press, pp. 159-170.

Pajón Leyra, I. (2009). "La noción de infinitud aplicada al movimiento: la tesis cratiliana de la total inestabilidad”. Ontology Studies. N. ${ }^{\circ}$. 9, pp. 139-153. Versión electrónica disponible en el Depósito Digital de Documentos, Universidad Autónoma de Barcelona. http://ddd.uab.es/record/53758?ln=ca. Pollmann, K. y Vessey, M. (eds.). (2005). Augustine and the Disciplines: from Cassiciacum to Confessions. Oxford University Press, pp. 206-231.

Pollmann, K. y Vessey, M. (2005a). "Augustine's hermeneutics as a universal Discipline?" Augustine and the Disciplines: from Cassiciacum to Confessions. Karla Pollmann and Mark Vessey (eds.). Oxford University Press, pp. 206-231.

Rincón González, A. (1992). Signo y lenguaje en San Agustín. Bogotá: Universidad Nacional de Colombia.

Rist, J. M. (1994). Augustine: ancient thought baptized. Cambridge: Cambridge University Press. 
Román, R. (2007). El enigma de la Academia de Platón: Escépticos contra dogmáticos en la Grecia Clásica. Córdoba: Berenice.

San Agustín (1955). "Confessionum”. En: Obras Completas de San Agustín. T. II. Traducción de Ángel Custodio Vega. Madrid: B.A.C.

San Agustín (2009a). Contra Academicos. Introducción de Julio García Álvarez y Jaime García Álvarez. Edición bilingüe. Madrid: Encuentro.

San Agustín (2009b). De civitate Dei. Edición de Santos Santamaría del Río, Miguel Fuertes Lanero, Victorino Capánaga y Teodoro Calvo Madrid. Madrid: B.A.C.

San Agustín (1969a). "De Doctrina Christiana". En: Obras Completas de san Agustín. T. XV. Traducción de Balbino Martín. Madrid: B.A.C.

San Agustín (1969b). "De Genesi at litteram". En: Obras Completas de san Agustín. T. XV. Edición de Balbino Martín Pérez. Madrid, B.A.C.

San Agustín (2003). De Magistro. Traducción de Atilano Domínguez. Madrid: Trotta.

San Agustín (2006). "De Trinitate”. En: Obras completas de san Agustín. T. XV. Traducción de Luis Arias. Madrid: B.A.C.

San Agustín (1988). "De immortalitate animae". En: Obras completas de san Agustín. T. XXXIX. Traducción de Lope Cilleruelo. Madrid: B.A.C.

San Agustín (1946). "Soliloquiorum". En: Obras Completas de san Agustín. T. I. Traducción de Victorino Capánaga. Madrid: B.A.C.

Sexto Empírico. (1997). Contra los profesores. Traducción de Carlos García Gual. Madrid: Gredos.

Stump, E. y Kretzman, N. (eds.). (2001). The Cambridge Companion to Augustine. Cambridge University Press.

Todorov, T. (1991). Teorías del símbolo. Traducción de Francisco Rivera.

Caracas: Monte Ávila Editores. 